\title{
PURIFICAÇÃO E CARACTERIZAÇÃO DO ÓLEO DA MICROALGA Scenedesmus accuminatus VISANDO À PRODUÇÃO DE BIODIESEL
}

\author{
K. B. Z. F. BRANCO ${ }^{1}$, E. TREVISAN ${ }^{1}$, N. V. dos REIS ${ }^{1}$ e P. A. ARROYO ${ }^{1}$ \\ ${ }^{1}$ Universidade Estadual de Maringá, Departamento de Engenharia Química \\ E-mail para contato: kemelybruna@hotmail.com
}

\begin{abstract}
RESUMO - A utilização de microalgas na produção de biodiesel se deve, principalmente, à alta produtividade e teor de lipídeos. No entanto, devido à forma com que os lipídeos são classificados na literatura, deve-se verificar e distinguir entre o teor de lipídeos totais e o teor de lipídeos neutros, sendo estes compostos de interesse para a produção de biodiesel. Assim, o objetivo deste trabalho foi determinar o teor de lipídeos de interesse para produção de biodiesel na microalga Scenedesmus accuminatus e caracterizá-lo, determinando-se o índice de acidez e a composição em ácidos graxos. Por meio do estudo, observou-se um teor de lipídeos neutros de 5,19\%. Para tanto, realizou-se uma adsorção seletiva em coluna recheada com carvão ativado de osso, para a remoção dos compostos indesejáveis para a reação de transesterificação. $O$ processo de purificação se mostrou eficiente, conforme comprovado por espectroscopia UV-vis. O índice de acidez de 6,89 $\mathrm{mg} \mathrm{KOH/g}$ de óleo indica a necessidade do uso de catalisadores ácidos e a composição em ácidos graxos é semelhante à composição do óleo de soja, o que pode levar à produção de um biodiesel de qualidade, conforme as normas da ANP.
\end{abstract}

\section{INTRODUÇÃ̃}

As microalgas são reconhecidas como a forma de vida mais antiga (Brennan e Owende, 2010) e, atualmente, tem sido estudada a sua utilização na produção de biodiesel, devido ao elevado teor de lipídeos e produtividade. Além de lipídeos, as microalgas possuem, também, na sua composição proteínas, carboidratos e ácidos nucléicos (Becker, 1994). No entanto, é a sua composição de lipídeos que tem gerado o grande interesse na sua utilização para produção de biodiesel.

Os lipídeos são geralmente classificados em grupos baseados na polaridade da molécula. No entanto, estes grupos podem ser nomeados diferentemente, dependendo de cada autor, como por exemplo, Halim et al. (2012) que classificam os lipídeos em dois grupos, sendo estes lipídeos neutros (acilgliceróis, ácidos graxos livres, hidrocarbonetos, esteróis, ceras, ésteres de esteróis, álcoois, pigmentos) e lipídeos polares (fosfolipídeos e glicolipídeos). Já Krohn et al. (2011) classificam os lipídeos em três grupos, os quais são nomeados de lipídeos neutros (acilgliceróis, ácidos graxos livres, hidrocarbonetos, esteróis, ceras, ésteres de esteróis, álcoois), lipídeos brutos (lipídeos neutros + pigmentos) e lipídeos totais (lipídeos brutos + fosfolipídeos e glicolipídeos). 


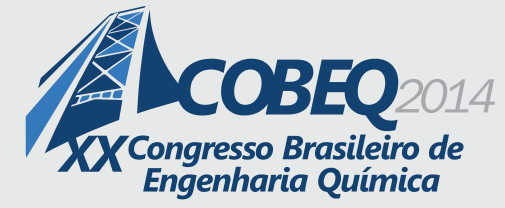

Para a produção de biodiesel puro apenas os triacilglicerídeos e os ácidos graxos livres são os lipídeos de interesse, sendo os mesmos classificados como lipídeos neutros. No entanto, as classes dos lipídeos neutros também possuem compostos que não são convertidos em biodiesel, tais como hidrocarbonetos, esteróis, cetonas e pigmentos (Hu et al., 2008; Wahlen et al., 2011; Krohn et al., 2011; Halim et al., 2012, Nascimento et al., 2013).

Devido à forma com que os lipídeos são classificados deve-se observar se o teor de lipídeos descrito na literatura se refere ao teor de lipídeos totais ou aos compostos de interesse para a produção de biodiesel, ou seja, os triacilglicerídeos e ácidos graxos livres.

$\mathrm{Na}$ literatura o que geralmente se encontra é o teor de lipídeos totais das microalgas, sendo que estes variam consideravelmente de uma espécie para outra, com valores entre 5 a $77 \%$ em termos de biomassa seca (Chisti, 2007). O mesmo pode ser aumentado otimizando os fatores relacionados ao crescimento da microalga, tais como o controle do nível de nitrogênio, luminosidade, temperatura, salinidade, concentração de $\mathrm{CO}_{2}$ e procedimento de colheita (Brennan e Owende, 2010).

Outra característica importante para produção do biodiesel é a composição em ácidos graxos do óleo a ser utilizado. A maioria dos lipídeos presentes nas microalgas contém ácidos graxos que possuem de 12 a 22 carbonos e podem ser saturados ou insaturados (Medina et al., 1998, Halim et al., 2012). Segundo Ramos et al. (2009) e Nascimento et al. (2013) a composição e o número de insaturações dos ácidos graxos influenciam diretamente as características finais do biodiesel, tais como número de cetano, saponificação, grau de insaturação, índice de iodo, ponto de entupimento de filtro a frio e outros.

Assim, o objetivo deste trabalho foi determinar o teor de lipídeos de interesse na microalga Scenedesmus accuminatus para a produção de biodiesel e caracterizá-lo, determinando o índice de acidez e a composição em ácidos graxos.

\section{MATERIAIS E MÉTODOS}

\subsection{Obtenção da biomassa seca}

As cepas da microalga Scenedesmus accuminatus foram cultivadas em meio MC, conforme proposto por Watanabe (1960), com uma diluição volumétrica de inóculo:meio nutricional:água deionizada de 1:1:8. A colheita da biomassa foi realizada por floculação prévia da biomassa, utilizando-se o floculante natural Tanfloc-SL. A operação de floculação foi seguida por decantação e filtração em tela de 20 mesh, para, então, obter-se a biomassa algácea.

A secagem da biomassa algácea foi realizada em estufa, na temperatura de $60{ }^{\circ} \mathrm{C}$, até massa constante. Após a colheita e secagem a mesma foi macerada e armazenada em potes plásticos, em temperatura próxima a $-8{ }^{\circ} \mathrm{C}$, para que fossem mantidas as propriedades da biomassa. 


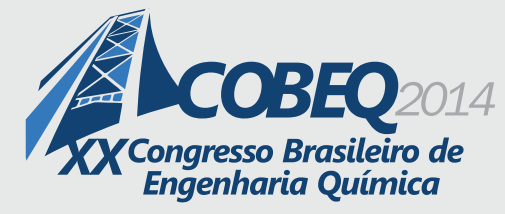

\subsection{Extração e purificação do óleo}

O óleo da microalga Scenedesmus accuminatus foi extraído pelo método de lavagem sucessiva, utilizando n-hexano como solvente, conforme descrito por Baumgärtner et al. (2013). Primeiramente pesou-se 1 grama de biomassa seca em um tubo tipo Falcon, ao qual foram adicionados $10 \mathrm{~mL}$ de solvente. Em seguida, o tubo foi colocado em um banho, sob agitação, a 60 ${ }^{\circ} \mathrm{C}$, por $30 \mathrm{~min}$. Em seguida, a amostra foi centrifugada por 5 minutos a $4000 \mathrm{rpm}$ e o solvente sobrenadante foi transferido para um balão previamente pesado (P1). Ao tubo contendo a biomassa residual adicionaram-se mais $10 \mathrm{~mL}$ de solvente e este foi levado novamente ao banho, por mais 30 minutos. Esse processo se repetiu por 6 vezes. Ao final, o solvente no balão, contendo a matéria graxa, foi evaporado em um evaporador rotativo. $\mathrm{O}$ balão contendo a matéria graxa foi seco em estufa, a $60{ }^{\circ} \mathrm{C}$, até massa constante (P2). O teor de lipídeos totais foi determinado a partir da diferença de massa entre P2 e P1.

Após este procedimento de extração da matéria graxa, foi necessário realizar a purificação da mesma para remover compostos indesejáveis para a reação de transesterificação, tais como clorofila, fosfolípidios e glicolipídios.

A purificação do óleo foi realizada utilizando-se um processo de adsorção seletiva em coluna de leito fixo. Primeiramente, a matéria graxa obtida anteriormente foi diluída em n-hexano na proporção 1:50 ( $\left.\mathrm{m}_{\text {biomassa seca }} \mathrm{mL}_{\text {n-hexano }}\right)$ e o leito foi recheado com carvão ativado de osso animal granulado, cedido pela empresa Bonechar Carvão do Brasil LTDA. Utilizou-se uma coluna de vidro de aproximadamente $30 \mathrm{~cm}$ de altura, contendo $6 \mathrm{~g}$ de carvão ativado. O solvente n-hexano, utilizado para eluir o extrato pela coluna, foi recuperado em um evaporador rotativo e os lipídeos neutros obtidos foram secos em estufa a $60{ }^{\circ} \mathrm{C}$, para a completa remoção do solvente. Cabe ressaltar que foram realizadas doze extrações e purificações.

Com o intuito de verificar se o processo de purificação foi eficiente na remoção dos pigmentos e outros compostos, realizou-se a análise por espectroscopia de varredura no UV-vis da amostra na faixa de 200 a $1100 \mathrm{~nm}$ após a extração e após a purificação. Os espectros obtidos foram comparados com o espectro de uma amostra de óleo de soja comercial e de uma amostra ácido oleico (P.A.).

\subsection{Caracterização do óleo}

Para a caracterização do óleo obtido foi determinado apenas o índice de acidez e a composição em ácidos graxos obtidos frente à extração e purificação, conforme descrito a seguir. Cabe ressaltar que a caracterização do óleo foi realizada em triplicata.

Determinação do índice de acidez: A determinação do índice de acidez foi realizada segundo a metodologia proposta pelo Instituto Adolf Lutz (1985). Para isso, $2 \mathrm{~g}$ de óleo foram colocadas em um erlenmeyer de $250 \mathrm{~mL}$ e diluída em $25 \mathrm{~mL}$ da solução de éter:álcool (2:1). Em seguida, foram adicionadas 2 gotas de indicador fenolfotaleína $1 \%$, sendo a amostra titulada com uma solução de hidróxido de sódio $0,01 \mathrm{~mol} / \mathrm{L}$, até o aparecimento de uma coloração rósea, a 


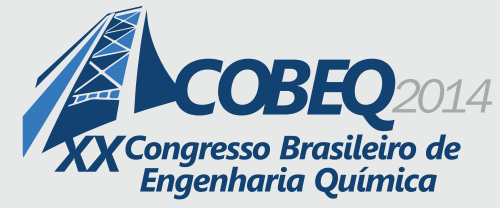

19 a 22 de outubro de 2014

Florianópolis/SC

qual deve persistir por aproximadamente 30 segundos. Assim, o índice de acidez é dado pela Equação 1:

$$
\text { Índice de acidez }=\frac{V X f X 0,561}{P_{o}}(\mathrm{mg} \mathrm{KOH} / \mathrm{g} \text { óleo })
$$

Determinação da composição em ácidos graxos do óleo: Devido ao alto índice de acidez apresentado pelo óleo de microalga, utilizou-se a metodologia de esterificação de lipídeos (Hartmann e Lago, 1973), na qual: Pesaram-se $100 \mathrm{mg}$ de amostra de óleo em um tubo de ensaio; adicionaram-se $4 \mathrm{~mL}$ de solução 0,5 equivalente/ $\mathrm{L}$ de $\mathrm{NaOH}$ em metanol; fechou-se bem o tubo de ensaio, o qual foi aquecido em banho de água em ebulição, até dissolver os glóbulos de óleo e a solução tornar-se transparente; esfriou-se o tubo de ensaio em água corrente e adicionaram 5 $\mathrm{mL}$ do reagente esterificante (metanol); o tubo foi novamente aquecido em banho, sendo adicionados $4 \mathrm{~mL}$ da solução saturada de cloreto de sódio; agitou vigorosamente o tubo por 30 segundos e, após, adicionaram-se $5 \mathrm{~mL}$ do solvente n-heptano; o tubo foi novamente agitado por mais 30 segundos. Deixou-se o tubo em repouso por aproximadamente 90 minutos, na geladeira; o sobrenadante foi utilizado para análise do óleo por cromatografia em fase gasosa. O perfil em ácidos graxos foi determinado usando um cromatógrafo gasoso (Varian, modelo CP-3800), com detector de ionização de chamas (DIC), contendo uma coluna capilar BP-X70 - SGE de $30 \mathrm{~m} \mathrm{x}$ $0.25 \mathrm{~mm}$. Como gás de arraste uutilizou-se hélio, numa razão split de 1:10. A análise foi realizada com programação de temperatura da coluna, iniciando a $140{ }^{\circ} \mathrm{C}$, com aquecimento até $250{ }^{\circ} \mathrm{C}$ a uma taxa de $5^{\circ} \mathrm{C} / \mathrm{min}$. A temperatura do detector foi de $220^{\circ} \mathrm{C}$ e do injetor de $260^{\circ} \mathrm{C}$.

\section{RESULTADOS E DISCUSSÃO}

\subsection{Extração e purificação do óleo}

Por meio do método de extração sucessiva, foi possível obter um teor de lipídeos totais de $9,68 \pm 1,14 \%$ na biomassa seca da microalga Scenedesmus accuminatus, valor abaixo do valor descrito por Mata et al. (2010) de 19,6 a 21,1\% e maior do que 5,14\% obtido por Baumgärtner et al. (2013). Esta diferença entre o valor obtido e o descrito por Mata et al. (2010), pode ter ocorrido devido ao teor de lipídios totais presentes na biomassa da microalga depender diretamente do meio de cultivo e parâmetros de cultivo da mesma, além da diferença nos métodos de extração e nas características do solvente.

Segundo Baumgärtner et al. (2013), a extração sucessiva utilizando como solvente o nhexano se mostrou a mais adequada, pois mesmo obtendo um teor de lipídeos totais inferior ao descrito na literatura, a mesma levou a uma composição em ácidos graxos característico da maioria das oleaginosas utilizadas para a produção de biodiesel, o que pode levar a ganhos significativos na qualidade final do biodiesel.

Porém, mesmo quando a extração é realizada utilizando apenas solvente apolar, ainda se faz necessário a purificação do extrato obtido para se determinar a quantidade real de 
acilglicerídeos presentes na biomassa seca da microalga, além, de eliminar componentes indesejáveis para a transesterificação, como, por exemplo, pigmentos.

Assim, o extrato obtido foi diluído em n-hexano e esta solução foi passada pela coluna recheada com carvão ativado, conforme descrito anteriormente. Após a purificação dos lipídeos totais foi obtido um teor mássico de lipídeos neutros de $5,19 \pm 0,74 \%$. Por meio da espectroscopia de varredura UV-vis realizada nas amostras foi possível observar a eficiência do processo de purificação, conforme mostra a Figura 1 e a Tabela 1.

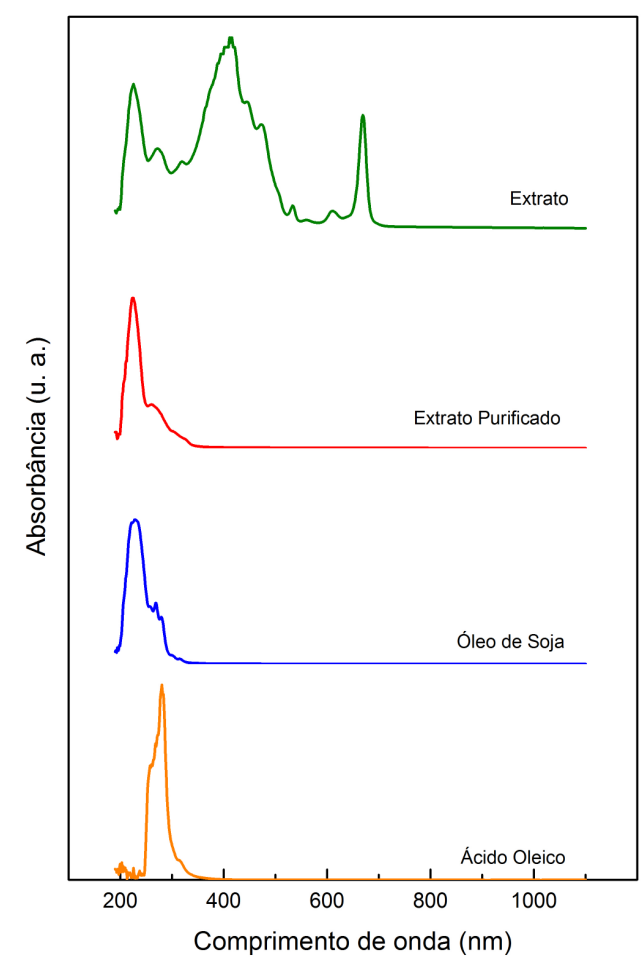

Figura 1 - Espectroscopia no UV-vis.

Tabela 1 - Comprimento de onda das bandas principais observadas nos espectros no UV-vis.

\begin{tabular}{|c|c|c|c|c|}
\hline \multirow{2}{*}{ Banda característica } & \multicolumn{4}{|c|}{ Comprimento de onda (nm) } \\
\cline { 2 - 5 } & Extrato & Purificada & Óleo de soja & Ácido oleico \\
\hline Lipídeos & 225 & 223 & 229 & - \\
\hline Lipídeos & 272 & 261 & 269 & 270 \\
\hline Clorofila $a^{*}$ & 411 & - & & \\
\hline Caroteno* & 473 & - & & \\
\hline Clorofila $a^{*}$ & 533 & - & \\
\hline Clorofila $a^{*}$ & 611 & - & & \\
\hline Clorofila $a^{*}$ & 669 & - & \\
\hline
\end{tabular}

*Maestrin et al. (2009). 


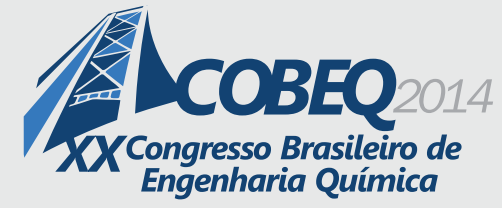

Por meio da Figura 1 e da Tabela 1 é possível observar a eficiência do processo de purificação, ficando claro o desaparecimento das bandas características da clorofila $a$ e dos carotenos. A presença predominante de triacilglicerídeos na amostra do extrato purificado é confirmada pela comparação com os espectros obtidos para o óleo de soja refinado e para o ácido oleico, os quais apresentam apenas bandas intensas em 229 e $269 \mathrm{~nm}$ e $270 \mathrm{~nm}$, respectivamente, atribuídas aos lipídeos, que são predominantemente triacilglicerídeos para o óleo comercial.

\subsection{Caracterização do óleo}

O produto obtido por meio da purificação em coluna de leito fixo foi utilizado para determinação do índice de acidez e composição em ácidos graxos do óleo da microalga.

Índice de acidez: Corroborando com os dados obtidos por Baumgärtner et al. (2013), o índice de acidez do óleo da microalga obtido foi de $6,89 \mathrm{mg} \mathrm{KOH} / \mathrm{g}$, indicando que o melhor processo para produção de ésteres é a via ácida.

Composição em ácidos graxos: A partir da composição em ácidos graxos da microalga Scenedesmus accuminatus obtido, pode-se observar que 33,62\% dos ácidos graxos presentes são saturados, 43,93\% monoinsaturados e $22,45 \%$ poliinsaturados. Este perfil obtido é semelhante ao encontrado por Baumgärtner et al. (2013) para a mesma microalga, sendo este composto de $33,18 \%$ de ácidos graxos saturados, $26,22 \%$ monoinsaturados e $40,60 \%$ poliinsaturados. Já segundo Nascimento et al. (2013), a composição em ácidos graxos obtidos a partir da biomassa da microalga Scenedesmus obliquus é composto de 70,83\% de ácidos graxos saturados, $21,71 \%$ monoinsaturados e $7,46 \%$ poliinsaturados.

Tabela 2 - Composição em ácidos graxos do óleo purificado da microalga Scenedesmus accuminatus

\begin{tabular}{|c|c|c|c|c|c|c|c|}
\hline $\begin{array}{c}\text { Ácido } \\
\text { Graxo }\end{array}$ & $\begin{array}{c}\% \\
(\mathbf{m} / \mathbf{m})\end{array}$ & $\begin{array}{c}\text { Ácido } \\
\text { Graxo }\end{array}$ & $\begin{array}{c}\mathbf{\%} \\
(\mathbf{m} / \mathbf{m})\end{array}$ & $\begin{array}{c}\text { Ácido } \\
\text { Graxo }\end{array}$ & $\begin{array}{c}\text { \% } \\
(\mathbf{m} / \mathbf{m})\end{array}$ & $\begin{array}{c}\text { Ácido } \\
\text { Graxo }\end{array}$ & $\begin{array}{c}\mathbf{\%} \\
(\mathbf{m} / \mathbf{m})\end{array}$ \\
\hline $\mathrm{C} 8: 0$ & 2,833 & $\mathrm{C} 14: 1$ & 0,9469 & $\mathrm{C} 17: 0$ & 0,8101 & $\mathrm{C} 20: 0$ & 0,9123 \\
\hline $\mathrm{C} 10: 0$ & 7,151 & $\mathrm{C} 15: 0$ & 1,068 & $\mathrm{C} 18: 0$ & 2,334 & $\mathrm{C} 20: 1$ & 2,857 \\
\hline $\mathrm{C} 11: 0$ & 0,6207 & $\mathrm{C} 15: 1$ & 0,4561 & $\mathrm{C} 18: 1$ & 38,15 & $\mathrm{C} 21: 0$ & 0,4456 \\
\hline $\mathrm{C} 13: 0$ & 0,8844 & $\mathrm{C} 16: 0$ & 14,83 & $\mathrm{C} 18: 2$ & 16,56 & $\mathrm{C} 22: 0$ & 0,7424 \\
\hline $\mathrm{C} 14: 0$ & 0,9887 & $\mathrm{C} 16: 1$ & 1,518 & $\mathrm{C} 18: 3$ & 3,085 & $\mathrm{C} 20: 3$ & 2,807 \\
\hline
\end{tabular}

As maiores proporções de ácidos graxos extraídos, aproximadamente $70 \%$, foram de C18:1, C18:2 e C16:0 (em ordem decrescente), com a predominância de ácidos graxos insaturados. Este perfil leva a ganhos na propriedade ponto de entupimento do filtro a frio, pois o ponto de fusão dos ácidos graxos saturados é maior que o ponto de fusão dos ácidos graxos insaturados. Portanto, quando um biodiesel rico em ácidos graxos saturados é resfriado, estes ácidos graxos são os primeiros a se precipitar (Nascimento et al., 2013), não sendo adequados para o uso em regiões de clima frio. 


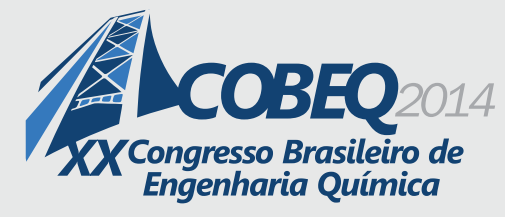

19 a 22 de outubro de 2014

Florianópolis/SC

Observa-se, também, a presença de aproximadamente $10 \%$ de ácidos graxos menores que C11:0, que pode afetar negativamente o ponto de fulgor, mas positivamente a viscosidade. Por outro lado, há mais de 7,5\% de ácidos graxos maiores que C20:0, que podem afetar negativamente a viscosidade, mas positivamente o ponto de fulgor. Logo, o perfil obtido indica que o biodiesel produzido a partir da biomassa de microalgas tende a ter um ganho na propriedade de entupimento do filtro a frio, devido à presença de ácidos graxos insaturados, por outro lado, pode apresentar perdas na estabilidade oxidativa. Porém, ressalta-se, também, que os ácidos graxos predominantes obtidos a partir da biomassa da microalga Scenedesmus accuminatus é igual aos principais ácidos graxos presentes no óleo de soja, principal matériaprima utilizada na produção de biodiesel atualmente no Brasil (Ramos et al., 2009; Leung et al., 2010), levando a ganhos na qualidade final do biodiesel.

\section{CONCLUSÕES}

$\mathrm{Na}$ determinação do teor de lipídeos presentes na microalga Scenedesmus accuminatus foi possível observar que o método de extração e o tipo de solvente utilizado têm influência direta no teor de lipídeos obtidos. Independente do solvente utilizado é necessário realizar a purificação dos lipídeos obtidos com o intuito de eliminar os compostos indesejáveis para a reação de transesterificação, como, por exemplo, os pigmentos. De fato, no processo de purificação, o uso de uma coluna recheada com carvão ativado de osso se mostrou extremamente eficiente na remoção dos compostos indesejáveis para a reação de transesterificação, como foi comprovado qualitativamente pela espectroscopia UV-vis.

A caracterização do óleo da microalga Scenedesmus accuminatus mostrou um alto índice de acidez indicando assim a necessidade do uso de catalisadores ácidos para a reação de transesterificação. A composição em ácidos graxos do óleo da microalga e o perfil de ésteres são semelhantes à composição em ácidos graxos do óleo de soja, principal matéria-prima hoje utilizada para a produção de biodiesel no Brasil, o que pode levar à produção de um biodiesel de qualidade.

\section{REFERÊNCIAS}

BAUMGÄRTNER, T. R. D. S., BURAK, J. A. M., ZANIN, G. M., BAUMGÄRTNER, D., SÉBASTIEN, N. Y., ARROYO, P. A. Different methods for extracting oil from the microalga Scenedesmus accuminatus for biodiesel production. Br J Anal Chem, v. 10, p. 441-445, 2013.

BECKER, E. W. Microalgae: Biotechnology and Microbiology. Cambridge University Press, 1994, 293p.

BRENNAN, L.; OWENDE, P. Biofuels from microalgae: A review of technologies for production, processing, and extractions of biofuels and co-products. Renew Sust Energ Rev, v. 14, n. 2, p. 557-577, fev. 2010.

CHISTI, Y. Biodiesel from microalgae. Biotechnol Adv, v. 25, n. 3, p. 294-306, mai.-jun. 2007. 
HALIM, R. Extraction of oil from microalgae for biodiesel production: a review. Biotechnol Adv, v. 30, n. 3, p. 709-732, mai.-jun. 2012.

HARTMANN, L.; LAGO, R.C.A.. Rapid preparation of fatty acid methyl esters from lipids. Lab Practices, v. 22, p. 475-477, jul. 1973.

HU, Q., SOMMERFELD, M., JARVIS, E., GHIRARDI, M., POSEWITZ, M.,SEIBERT, M., DARZINS, A. Microalgal triacylglycerols as feedstocks for biofuel production: perspectives and advances. The Plant Journal, v. 54, 621-639, 2008.

INSTITUTO ADOLFO LUTZ. Métodos Físico-químicos para Análise de Alimentos. São Paulo:Câmara Brasileira do Livro, v.1, $3^{\text {a }}$ ed., 1985.

KROHN, B. J., MCNEFF, C. V., YAN, B., NOWLAN, D. Production of algae-based biodiesel using the continuous catalytic Mcgyan ${ }^{\circledR}$ process. Bioresource Technol, v. 102, n.1, p. 94100, jan. 2011.

LEUNG, D. Y. C.; WU, X.; LEUNG, M. K. H. A review on biodiesel production using catalyzed transesterification. App Energ, v. 87, n. 4, p. 1083-1095, abr. 2010.

MATA, T. M.; MARTINS, A. A.; CAETANO, N. S. Microalgae for biodiesel production and other applications: a review. Renew Sust Energ Rev, v. 14, n. 1, p. 217-232, jan. 2010.

MAESTRIN, A. P. J., NERI, C. R., OLIVEIRA, K. T., SERRA, O. A., IAMAMOTO, Y. Extração e purificação de clorofila a, da alga Spirulina maxima: um experimento para os cursos de química. Química Nova, v. 32, n. 6, p. 1670-1672, 2009.

MEDINA, A. R., GRIMA, E. M., GIMÉNEZ, A. G., GONZÁLEZ, M. J. I. Downstream processing of algal polyunsaturated fatty acids. Biotechnol Adv, v. 16, n. 3, p. 517-580, maio 1998.

NASCIMENTO, I. A., MARQUES, S. S. I., CABANELAS, I.T. D., PEREIRA, S. A., DRUZIAN, J. I., SOUZA, C. O., VICH, D. V., CARVALHO, G. C., NASCIMENTO, M. A. Screening microalgae strains for biodiesel production: lipid productivity and estimation of fuel quality based on fatty acids profiles as selective criteria. BioEnergy Research, v. 6, n. 1, p. 1-13, mar. 2013.

RAMOS, M. J.,FERNÁNDEZ, C. M., CASAS, A., RODRÍGUEZ, L., PÉREZ, A.Influence of fatty acid composition of raw materials on biodiesel properties. Bioresource Technol, v. 100, n. 1, p. 261-268, jan. 2009.

WAHLEN, B. D., WILLIS, R. M., SEEFELDT, L. C. Biodiesel production by simultaneous extraction and conversion of total lipids from microalgae, cyanobacteria, and wild mixedcultures. Bioresource Technol,v. 102, n. 3, p. 2724-2730, fev. 2011.

WATANABE, A. List of algal strains in collection at the institute of applied microbiology, University of Tokyo. J. Gen Appl Microbiol, v.6, n.4, 1960. 